\title{
Prevalence of the red mite (Dermanyssus gallinae) in layer flocks in four districts in northern West Bank, Palestine
}

\author{
Rateb Aref Othman ${ }^{1}$, Jihad M. Abdallah ${ }^{2}$, Jamal Abo-Omar $^{2 *}$ \\ ${ }^{1}$ Faculty of Veterinary Medicine, An Najah National University, Nablus, Palestine \\ ${ }^{2}$ Department of Animal Production, Faculty of Agriculture, An Najah National University, Nablus, Palestine; \\ *Corresponding Author: aboomar57@najah.edu
}

Received 30 October 2011; revised 31 December 2011; accepted 5 January 2012

\begin{abstract}
An experiment was conducted to investigate the prevalence of the red mite (Dermanyssus gallinae) in layer farms in four districts of northern West Bank, Palestine. The four districts were: Nablus, Tulkarm, Tubas, and Jenin. A total of 225 layer farms were investigated for infection with the parasite during the period from September 2009 to August 2010. The highest prevalence of the red mite was observed in the district of Tulkarm $(18.3 \%, 25.5 \%, 32.7 \%$ and $47.3 \%$, for the districts of Nablus, Jenin, Tubas, and Tulkarm, respectively) which can be explained by the hot humid climate in the district and insufficient cleaning. Infection with the red mite was highest in summer (43.8\%) and lowest in winter (12\%). The high infection rates observed in this study reflect the poor management and housing conditions, characteristic of layer farms in the study region.
\end{abstract}

Keywords: Prevalence; Red Mite; Layer Farms; Northern West Bank

\section{INTRODUCTION}

The poultry industry plays an important role in Palestinian agricultural economy. It contributes $40 \%$ to $50 \%$ of the income of the animal production sector $(12 \%$ to $15 \%$ of the agricultural income). The recent statistics showed that the total population of layer hens and broilers to be 3.5 and 39 million respectively [1]. The small investments in the local poultry sector are associated with poor status of the sector. The local poultry sector is characterized by poor facilities and poor management which favor infections and parasitic invasion, especially the Dermanyssus gallinae, the main external parasite of layer hens. This parasite causes important economic losses by reducing productivity [2-6].

The life cycle of the parasite is relatively short (less than 7 days) [7]: adult females lay eggs 12 - 24 hours after they get their first blood meal, which hatch within 48 to 72 hours. The 6-legged larvae molt within 24 to 48 hours, which then develop into first-stage blood-sucking nymphs without having any blood meal. They then molt into second-stage nymphs within 24 - 48 hours, and then soon molt to the adult stage. Red mite infection causes many harm effects to the host as anemia, dermatitis, restlessness, and might lead to host death. Red mite can transmit the infection agents of different diseases as Newcastle virus, chicken pox virus, avian spirochetes, Salmonella enterica and agents of the fowl typhoid and cholera, in addition to its negative effects on human health through invasion of the skin which causes dermatologic problems $[4,6,8]$.

\section{MATERIALS AND METHODS}

This experiment was conducted during the period from September 2009 to August 2010. A total of 225 layer farms in four districts of northern West Bank, Palestine were investigated for infection with the parasite. The four districts were: Nablus, Tulkarm, Tubas, and Jenin. The layers raised in these farms were of the hi-line and totaled 141, 717 hens at different ages. To detect infection with the red mite, molting feather was collected in and beneath cages and fecal and dust samples were also collected from different areas beneath cages, $10 \mathrm{~cm}$ deep, using plastic jars covered with strong white sheets. These were labeled with farm name, the name of the district, and date of collection. The white sheets were kept for 24 hours then covered with plastic bags and sent to the parasitological lab of An-najah University for mite examination, following the procedure of Pavlicevic et al., 2007 [9].

The infection status of each farm was recorded (coded 
as $0=$ not infected or $1=$ infected). Prevalence of red mite (the proportion of infected farms) was calculated for each district and each season (winter, spring, summer, and autumn). The 95\% CI for estimates of the proportion infected were calculated based on a normal approximation as:

$$
\hat{p}_{i} \pm 1.96 \sqrt{\frac{\hat{p}_{i}\left(1-\hat{p}_{i}\right)}{n_{i}}},
$$

where $\hat{p}_{i}$ and $n_{i}$ are the estimated proportion of infected farms and the number of tested farms for the $i^{\text {th }}$ district (or season), respectively.

To test differences in prevalence of the red mite among districts and seasons, a binomial (logistic) regression was performed on the binary data $(0=$ not infected, $1=$ infected) with the logit used as link function. District and season were simultaneously fitted in the regression model as fixed factors. The odds ratios (relative risks) were estimated with Nablus used as base reference for districts and winter taken as base reference for seasons. In addition, the adjusted prevalence rates were obtained for each level of the studied factors (district and season) and compared. The analysis was carried out using the GENMOD procedure of SAS/STAT software, V9.0 for Windows (SAS Institute Inc., Cary, NC, USA).

\section{RESULTS}

The overall infection with the red mite of layer farms in the studied districts of northern West Bank was 30.7\% (95\% CI: 24.7, 36.7\%). The district of Tulkarm had the highest prevalence of red mites, while the district of Nablus had the lowest rate $(18.3 \%, 25.5 \%, 32.7 \%$ and 47.3\%, for the districts of Nablus, Jenin, Tubas, and Tulkarm, respectively), Table $\mathbf{1}$. Infection with the red mite was highest in summer followed by spring, autumn and

Table 1. Prevalence of red mite in layer farms in northern West Bank by district and season.

\begin{tabular}{|c|c|c|}
\hline Factor & Number of investigated farms & Prevalence $(95 \% \mathrm{CI})^{1}$ \\
\hline \multicolumn{3}{|c|}{ District } \\
\hline Nablus & 55 & $0.183(0.081,0.285)$ \\
\hline Jenin & 60 & $0.255(0.145,0.365)$ \\
\hline Tubas & 55 & $0.327(0.203,0.451)$ \\
\hline Tulkarm & 55 & $0.473(0.341,0.605)$ \\
\hline \multicolumn{3}{|c|}{$\underline{\text { Season }}$} \\
\hline Winter & 50 & $0.120(0.030,0.210)$ \\
\hline Spring & 53 & $0.358(0.229,0.487)$ \\
\hline Summer & 64 & $0.438(0.316,0.560)$ \\
\hline Autumn & 58 & $0.276(0.161,0.391)$ \\
\hline
\end{tabular}

${ }^{1}$ Unadjusted rates (prevalence rates for district are not adjusted for season and vice versa). then winter $(43.8 \%, 35.8 \%, 27.6 \%$ and $12 \%$, respectively).

The results from the logistic regression are in Table 2. Tulkarm had significantly higher prevalence (adjusted for season) than Nablus $(\mathrm{P}<0.01)$ and Jenin $(\mathrm{P}<0.05)$. The difference in prevalence between Tulkarm and Tubas was not statistically significant $(P=0.106)$. Similarly, no statistical differences were found among the districts of Tubas, Jenin, and Nablus ( $\mathrm{P}>0.05)$. With the district of Nablus taken as a reference, layer farms in Tulkarm had 4.27 times higher risk of infection with red mite than farms in Nablus, while layer farms in Jenin and Tubas had respectively 1.51 and 2.20 times higher risk of infection than farms in the district of Nablus.

Comparisons among seasons showed that infection with the red mite in winter was significantly lower than in summer $(\mathrm{P}=0.0004)$, spring $(\mathrm{P}=0.006)$ and autumn $(\mathrm{P}=0.046)$. No significant differences $(\mathrm{P}>0.05)$ were found among the other seasons (the difference between summer and autumn was close to be significant, $\mathrm{P}=$ 0.065). With winter taken as a reference, the risk of infection with red mites in summer was 6.12 times higher than in winter. The risk of infection in spring relative to winter was 4.35 times higher, while the risk of infection in autumn relative to winter was 2.92 times higher.

\section{DISCUSSION}

The results of this study showed that the prevalence of the parasite was highest $(\mathrm{P}<0.05)$ in the district of Tulkaremt compared to the other districts. This can be explained by the hot humid climate in the district (located close to the Mediterranean Sea) which enhances the de-

Table 2. Adjusted prevalence rates and odds ratios of infection with red mites in layer farms of northern West Bank (results from binomial logistic regression).

\begin{tabular}{|c|c|c|c|}
\hline Factor & $\begin{array}{c}\text { Adjusted } \\
\text { prevalence }^{1}\end{array}$ & Odds ratio $^{2}$ & $\begin{array}{l}\text { Significance of odds } \\
\text { ratios (P value) }\end{array}$ \\
\hline \multicolumn{4}{|c|}{$\underline{\text { District }}$} \\
\hline Nablus & $0.161^{\mathrm{B}^{*}}$ & 1.00 (Reference) & \\
\hline Jenin & $0.224^{\mathrm{B}}$ & 1.51 & 0.38 \\
\hline Tubas & $0.297^{\mathrm{B}}$ & 2.20 & 0.08 \\
\hline Tulkarm & $0.451^{\mathrm{A}}$ & 4.27 & 0.001 \\
\hline \multicolumn{4}{|c|}{$\underline{\text { Season }}$} \\
\hline Winter & $0.111^{\mathrm{B}^{*}}$ & 1.00 (Reference) & \\
\hline Spring & $0.353^{\mathrm{A}}$ & 4.35 & 0.006 \\
\hline Summer & $0.434^{\mathrm{A}}$ & 6.12 & 0.0004 \\
\hline Autumn & $0.268^{\mathrm{A}}$ & 2.92 & 0.046 \\
\hline
\end{tabular}

${ }^{1}$ Prevalence for district is adjusted for season and vice versa; ${ }^{2}$ Odds ratio measures risk of infection for each level of the factor relative to the reference level (Nablus for district and Winter for season); "Estimates in the same column with different alphabets are significantly different $(\mathrm{P}<0.05)$. 
velopment of the parasite. The life cycle of the parasite is about 6 days under day temperature of 30 to 35 and relative humidity of $70 \%$ to $80 \%$. It increases as temperature and humidity decrease. However, the optimum conditions for best growth and development of the parasite is $25^{\circ} \mathrm{C}$ to $30^{\circ} \mathrm{C}$ [10]. These conditions prevail in Tulkarem district particularly during summer, spring and autumn. Jenin is also located close to the sea and has hot humid climate, although less severe than Tulkarm, but had significantly less prevalence of the red mite. The infection rate in the other districts was also associated with the environmental conditions in each district. Tubas which ranked second in prevalence of the parasite is located in a valley land and has hot climate but less humid than Tulkarm and Jenin. Nablus had the lowest infection rate consistent with its moderate climatic conditions as it is located at higher altitude than the other districts.

Infection rates by season of the year were also consistent with the climatic conditions. The infection with the red mite parasite was highest in summer as associated with high temperature and high humidity followed by spring, autumn, and then winter. The activity of insects which act as transmitters for the parasite increases in spring and summer which increases the infection rate in this period of the year. The infection with the parasite occurs in all seasons enhanced by its ability to survive for 34 weeks without a blood meal [11].

Litter cleaning is another factor which likely influenced the differences in prevalence rates. In a complementary investigation, 40 farms were randomly sampled from each district (10 from those previously sampled each season) and farmers were asked about litter cleaning frequency per season. The results (Table 3) showed that litter cleaning is done more frequently by the farmers in Nablus and Jenin than Tulkarm and Tubas, particularly in Summer.

The overall prevalence of the red mite in layer farms of the studied region was relatively high (30.7\%). This may be due to different factors including low experience of farmers, poor housing conditions, and poor management practices. Cleaning is usually not done with sufficient frequency and when done the feces is deposited close to the farm. In addition, some farmers reuse previously used unclean egg collection trays which favor re-infection with the parasite. To reduce infection, it is advised to use nonconventional practices to treat parasites like volatile plant oils and proteins rather than traditional insecticides [2-5,12-16] .

The economical losses to the farmers based on the observed infection rates may be substantial. Based on estimated decline in productivity of $5 \%$ and the total number of layers in local farms, the reduction in egg production is 4.5 million eggs per year with market value of about 2.25 million NIS (New Israeli Shekel).
Table 3. Percentage (\%) of farms according to litter cleaning frequency per season.

\begin{tabular}{|c|c|c|c|c|}
\hline \multirow{2}{*}{ Season } & \multirow{2}{*}{ District } & \multicolumn{3}{|c|}{ Frequency of litter cleaning/season } \\
\hline & & One time & Two times & Three times \\
\hline \multirow{4}{*}{ Winter } & Nablus & 10 & 80 & 10 \\
\hline & Jenin & 80 & 20 & 0 \\
\hline & Tubas & 90 & 10 & 0 \\
\hline & Tulkarm & 90 & 10 & 0 \\
\hline \multirow{4}{*}{ Spring } & Nablus & 80 & 20 & 0 \\
\hline & Jenin & 30 & 70 & 0 \\
\hline & Tubas & 90 & 10 & 0 \\
\hline & Tulkarm & 80 & 20 & 0 \\
\hline \multirow{4}{*}{ Summer } & Nablus & 10 & 20 & 70 \\
\hline & Jenin & 20 & 10 & 70 \\
\hline & Tubas & 60 & 40 & 0 \\
\hline & Tulkarm & 10 & 80 & 10 \\
\hline \multirow{4}{*}{ Autumn } & Nablus & 10 & 20 & 70 \\
\hline & Jenin & 80 & 20 & 0 \\
\hline & Tubas & 80 & 20 & 0 \\
\hline & Tulkarm & 80 & 20 & 0 \\
\hline \multirow{4}{*}{ All seasons } & Nablus & 27.5 & 35 & 37.5 \\
\hline & Jenin & 52.5 & 30 & 17.5 \\
\hline & Tubas & 80 & 20 & 0 \\
\hline & Tulkarm & 65 & 32.5 & 2.5 \\
\hline
\end{tabular}

\section{RECOMMENDATIONS}

Birds should be monitored and inspected for the red mite. The farming conditions should be also examined especially during hot humid seasons. However, housing conditions and management practices should be improved, particularly good cleaning and proper disposal of feces, and control of external carrier agents (birds, flies, etc). To reduce infection, it is advised to use nonconventional practices to treat parasites like volatile plant oils and proteins rather than traditional insecticides.

\section{REFERENCES}

[1] Palestinian Central Bureau of Statistics Website, 2009.

[2] Chirico, J. and Tauson, R. (2002) Traps containing acaricides for the control of Dermanyssus gallinae. Veterinary Parasitology, 110, 109-116. doi:10.1016/S0304-4017(02)00310-2

[3] Hamscher, G., Prieb, B., Hartung, J., Nogossek, M.L., Glunder, G. and Nau, H. (2003) Determination of propoxur residues in eggs by liquid chromatography-diode array detectionafter treatment of stocked housing facilities for the poultry red mite (Dermanyssus gallinae). Analytical Chemistry, 483, 19-26.

[4] Medevitt, R., Nister, A.J. and Huntley, J.F. (2006) Ability 
of a proteinase inhibitor mixture to kill poultry red mite, Dermanyssus gallinae in an in vitro feeding system. Veterinary Parasitology, 141, 380-385. doi:10.1016/j.vetpar.2006.05.013

[5] Nordenfors, H., Hoglund, J., Tauson, R. and Chirco, J. (2001) Effect of permethrin impregnated plastic strips on Dermanyssus gallinae in loose-housing systems for laying hens. Veterinary Parasitology, 102, 121-131. doi:10.1016/S0304-4017(01)00528-3

[6] Soulsby, E.J.L. (1982) Helmintis, arthropods and protozoa of domesticated animals. $7^{\text {th }}$ Edition, Philadelphia, 446-451.

[7] Saif, Y.M. (2003) Chicken mite parasitic diseases. Diseases of poultry. 11th Edition, Iowa State Press, Iowa.

[8] Thind, B.B. and Ford, H.L. (2007) Assessment of susceptibility of the poultry red mite Dermanyssus gallinae (Acari: Dermanyssidae) to some acaricides using an adapted filter paper based bioassay. Veterinary Parasitology, 144, 344-348. doi:10.1016/j.vetpar.2006.10.002

[9] Pavlicevic, A., Pavlovic, I. and Stajkovic, N. (2007) Method for early detection of poultry red mite dermanyssus gallinae. Biotechnology in Animal Husbandry, 23, 119-127. doi:10.2298/BAH0704119P

[10] Tucci, E.C., Prado, A.P. and Araujo, R.P. (2008) Development of Dermanyssus gallinae (Acari: Dermanyssidae) at different temperatures. Veterinary Parasitology, 155,
127-132. doi:10.1016/j.vetpar.2008.04.005

[11] Kirkwood A. (1963) Longevity of the mites Dermanyssue gallinae and lipinyssus sylviarum. Experimental Parasitology, 14, 358-366.

[12] Chauva, C. (1998) The poultry red mite Dermanyssus gallinae (De Geer, 1778): Current situation and future prospects for control. Veterinary Parasitology, 79, 239245. doi:10.1016/S0304-4017(98)00167-8

[13] Hoglund, J., Nordenfors, H. and Liggla, A. (1995) Prevalence of the poultry red mite, Dermanyssus gallinae, in different types of production systems for egg layers in Sweden. Poultry Science, 74, 1793-1798.

[14] Kim, S., Yi, J.H., Tak, J.H. and Ahn, Y.J. (2004) Acaricidal activity of plant essential oils against Dermanyssus gallinae (Acari: Dermanyssidae). Veterinary Parasitology, 120, 297-304. doi:10.1016/j.vetpar.2003.12.016

[15] Norodenfors, H. and Hoglund, J. (2000) Long term dynamics of Dermanyssus gallinae in relation to mite control measures in aviary systems for layers. British Poultry Science, 41, 533-540. doi:10.1080/713654991

[16] Soon-li, K., Young, E.N., Ji-Hwan, Y., Byung, S.K. and Young, J.A. (2007) Contact and fumigant toxicity of oriental medicinal plant extracts against Dermanyssus gallinae (Acari: Dermanyssidae). Veterinary Parasitology, 145, 377-382. doi:10.1016/j.vetpar.2006.12.021 